\title{
Relato de Uso de Estratégias Ativas e Tecnologias Digitais no Ensino de TICs para Pedagogia EaD
}

\author{
Aracele Garcia de Oliveira Fassbinder, Cristiane Fortes Gris Baldan
}

\author{
IFSULDEMINAS - Campus Muzambinho \\ Caixa Postal 02 - CEP: 37890-000 - Muzambinho - MG - Brasil \\ \{aracele.garcia, cristiane.gris\}@muz.ifsuldeminas.edu.br
}

\begin{abstract}
This paper describes an experience report with the teaching of Information and Communication Technologies (ICTs) to 190 students of a class of the Licentiate Degree in Pedagogy, distance learning modality, during the year 2020, in a federal institution. The discipline was conducted through student-centered activities, whether individual or collective, and students had to demonstrate their ability to use tools, create learning objects and apply knowledge in contexts related to the categories covered in the course (School Management, Early Childhood Education and Elementary School I). Educational Design Research (EDR) guided the construction of this intervention. The use of active strategies, such as case-based, pair-based, and project-based learning, as well as digital tools, as opposed to traditional approaches to teaching informatics for the Distance Learning context, brought significant engagement and learning.
\end{abstract}

Resumo. Este artigo descreve um relato de experiência com o ensino de Tecnologias da Informação e Comunicação (TICs) para 190 estudantes de uma turma do curso de Licenciatura em Pedagogia, modalidade EaD, durante $o$ ano de 2020, em uma instituição pública federal. A disciplina foi conduzida com atividades centradas nos estudantes, sejam elas individuais ou coletivas, e os mesmos tiveram que demonstrar a capacidade de usar ferramentas, criar objetos de aprendizagem e aplicar o conhecimento em contextos relacionados às categorias abordadas no curso (Gestão Escolar, Educação Infantil e Ensino Fundamental I). A Educational Design Research (EDR) guiou a construção dessa intervenção. $O$ uso de estratégias ativas, tais como aprendizagem baseada em casos, em pares e em projetos, bem como ferramentas digitais, em oposição às abordagens tradicionais de ensino de informática para o contexto $E a D$, trouxe engajamento e aprendizagem significativa.

\section{Introdução}

O ensino das Tecnologias da Informação e Comunicação (TICs) em cursos formais de formação de professores é demasiado complexo, mas muito importante. O letramento digital e o desenvolvimento do pensamento computacional, além de serem habilidades requeridas para o século XXI, buscam complementar a formação interdisciplinar desses alunos, futuros profissionais. Adicionalmente, vale ressaltar que a formação inicial de professores em nível superior, segundo a Resolução 02/2015 e suas atualizações ${ }^{1}$, deve considerar estratégias que permitam aos licenciandos demonstrar o domínio de TICs para o desenvolvimento da aprendizagem.

Entretanto, muitas vezes, devido à pequena carga horária reservada para disciplinas ligadas ao ensino de TICs, e à priorização de disciplinas específicas do curso pelos estudantes, os professores encontram dificuldades em potencializar e aprofundar a

\footnotetext{
${ }^{1}$ http://portal.mec.gov.br/pet/323-secretarias-112877938/orgaos-vinculados-82187207/12861-formacao-superior-para-a-docencia-na-educacao-basica
} 
aprendizagem. Vieira e Freire (2018), por exemplo, buscaram desvelar a proposta de formação docente em licenciaturas de uma instituição de ensino em relação às TICs, e identificaram que "ainda existe uma grande divergência entre o modo como a tecnologia está presente na vida das pessoas e a forma como esses recursos estão sendo aproveitados como ferramenta metodológica que dê suporte ao processo de ensinar e aprender, dentro das instituições escolares”. Já Silva, Silva e França (2007) trazem à tona os desafios de implantar a competência número 05 da Base Nacional Comum Curricular - BNCC (Brasil, 2018), que trata da inclusão de aspectos de computação (Pensamento Computacional, Cultura Digital e Tecnologia Digital) no currículo da educação básica e as implicações na formação dos professores.

Considerando tal contexto, este artigo relata uma experiência de ensino de TICs aplicadas à Educação, em uma turma do curso de Licenciatura em Pedagogia EaD, durante o ano de 2020. A fim de minimizar as lacunas citadas anteriormente, fez-se uso de diversas estratégias ativas, no sentido de engajar os estudantes e, ao mesmo tempo, evidenciar que a transformação por meio das tecnologias só ocorre quando são usadas de forma integrada às estratégias pedagógicas significativas para o aluno.

\section{Métodos}

A estratégia metodológica principal que guiou a prática docente registrada neste relato, foi a Educational Design Research (EDR). De acordo com Plomp e Nieveen (2007) e Fassbinder, Fassbinder e Barbosa (2016), pode-se utilizá-la para produzir novas teorias, artefatos e práticas que representam ou potencialmente afetam o ensino e a aprendizagem. EDR é fundamentada na pesquisa-ação e nas ideias de design (Sein et al., 2011; Barab, 2014). Consiste, de forma geral, em quatro etapas principais: (i) reconhecimento da situação ou contexto; (ii) desenvolvimento da intervenção e refinamento a partir da avaliação de resultados; (iii) reflexão e aprendizagem e (iv) formalização da aprendizagem (descrição teórica da intervenção). De fato, trata-se de um percurso interativo e iterativo, pois uma vez que a intervenção é planejada e executada, o conhecimento obtido pode ser usado em refinamentos e melhorias sucessivas, conforme resultado que se espera alcançar.

\subsection{Reconhecimento da Situação ou Contexto}

Trata-se, como já descrito anteriormente, de uma experiência de ensino da disciplina intitulada "TICs na Educação" ministrada para uma turma de 190 alunos do $8^{\circ}$ período (último semestre) do curso de Licenciatura em Pedagogia EaD, em uma instituição pública federal. Na matriz curricular, a disciplina possui 45 horas e o conteúdo está distribuído em cinco semanas. A sexta semana é reservada para avaliações individuais e em grupo. A ementa consiste, de forma geral, em "Tecnologias; Espaços diferenciados de aprendizagem; Mídias na Educação; Informática na Educação; Softwares Educacionais; Objetos de Aprendizagem; Redes Virtuais de Aprendizagem”. É importante destacar que esse curso possui outras duas disciplinas relacionadas à informática, abordadas em semestres anteriores, a saber: Educação Aberta e a Distância ( $1^{\circ}$ período $)$ e Tecnologia Educacional ( $2^{\circ}$ período).

A disciplina tem como principais objetivos auxiliar o discente (futuro pedagogo) a compreender como as TICs podem ser usadas de forma crítica, significativa, reflexiva 
e ética em diversos contextos educacionais, principalmente no âmbito da Gestão Escolar e nas salas de aula da Educação Infantil e Ensino Fundamental I; identificar e selecionar as principais mídias e tecnologias digitais que podem ser utilizadas no contexto educacional; diferenciar os tipos de software, seus usos e formas de acesso (nuvem, celular, desktop, etc) no contexto educacional; utilizar e/ou criar tecnologias e recursos digitais, e incorporá-los à prática pedagógica para potencializar e transformar as experiências de aprendizagem e estimular uma atitude ativa e criativa dos atores envolvidos; criar um plano de aula intervencionista que envolva o uso de TICs como apoio ao ensino; compreender e projetar estratégias de aprendizagens ativas que façam uso de TICs como apoio ao ensino.

A fim de compreender o perfil da turma e a experiência dos alunos com TICs, foi aplicado um Diagnóstico Inicial da Disciplina de TIC na Educação utilizando-se o Google Forms. 100\% dos alunos responderam, o que totalizou 190 respostas únicas. A maior parte, $36.3 \%$ (69), relatou possuir idade entre 31 e 40 anos. Na sequência, $27.9 \%$ (53) entre 21 e 30 anos; $22.6 \%$ (43) entre 41 e 50; 13.2\% (25) acima de 51 anos.

Em relação à forma de acesso ao Ambiente Virtual de Aprendizagem (AVA) do curso, baseado no Moodle, 89.5\% (170) relataram acessar somente pelo computador conectado à internet. Uma pequena minoria acessa somente pelo celular (4); em outros locais, como no trabalho (1); e o restante (15) informou que alterna o acesso entre o computador e o celular. Cerca de 38.4\% (73) já atuam/trabalham na área de educação, enquanto $21.6 \%$ (41) relataram estar desempregados(as). O restante, 40\% (76) atua em outros setores, como comércio, serviço público, autônomo, etc. Aqueles que relataram fazer uso de TICs no trabalho citaram as seguintes ferramentas: Powerpoint para apresentação em slides; vídeos do YouTube; Word para edição de textos; Google Meet para reuniões (webconferências); softwares próprios da empresa; sistema acadêmico escolar; WhatsApp para comunicação com clientes e Instagram para divulgação de trabalhos; dentre outras.

Identificou-se que os alunos possuíam muito conhecimento com o uso do Gmail, Microsoft Word e YouTube. Em oposição, tinham pouco conhecimento sobre Google Docs, Google Forms, Google Drive e Twitter. Ao avançarmos um pouco mais, considerando ferramentas digitais do tipo "quadro virtual", "enquete", gravação e transmissão de vídeo, bem como ferramentas que permitem trabalhar com mapas conceituais de forma online, percebeu-se um conhecimento limitado em relação a elas, conforme descrito na Figura 1. Trata-se de ferramentas muito utilizadas durante o ensino remoto emergencial em tempos de pandemia da COVID-19.

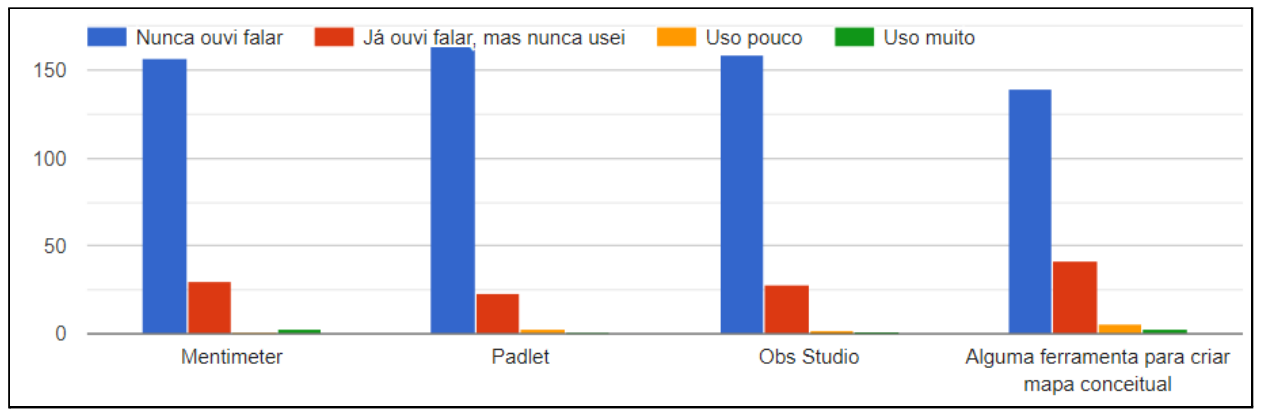

Figura 1. Conhecimento inicial dos estudantes sobre ferramentas digitais. 
Foi necessário compreender, também, o conhecimento da turma acerca da BNCC, uma vez que a competência geral número 5 aborda "Compreender, utilizar e criar tecnologias digitais de informação e comunicação de forma crítica, significativa, reflexiva e ética nas diversas práticas sociais (incluindo as escolares) para se comunicar, acessar e disseminar informações, produzir conhecimentos, resolver problemas e exercer protagonismo e autoria na vida pessoal e coletiva."2. Constatou-se, então, conforme dados da Figura 2, ser importante abordar esse tópico durante a disciplina de TICs na Educação.

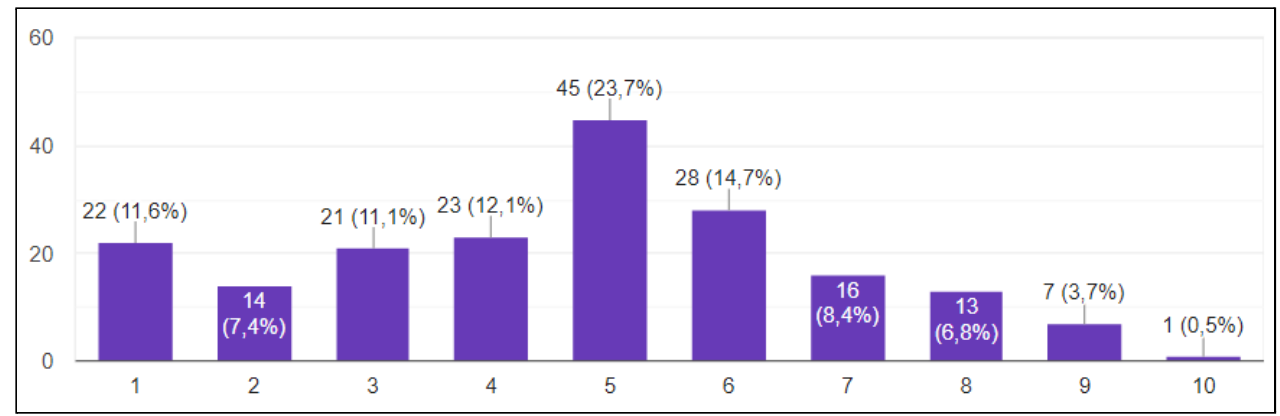

Figura 2. Conhecimento inicial dos estudantes sobre a Competência 5 da BNCC, onde 1=pouco conhecimento e 10=muito conhecimento.

\subsection{Desenvolvimento da Intervenção}

Para o Design de aprendizagem (ou Mapa de Atividades) da disciplina TICs na Educação, Tabela 1, levou-se em consideração os conhecimentos obtidos no diagnóstico anterior e a necessidade dos estudantes serem sujeitos da sua própria aprendizagem, fazendo-os compreender, na prática, que o uso de tecnologias no contexto escolar só faz sentido se eles, enquanto futuros pedagogos, integrá-las com estratégias ativas, seja no âmbito da Educação Infantil, Ensino Fundamental I ou Gestão Escolar.

Assim, fez-se uso de pelo menos quatro estratégias ativas de ensino-aprendizagem, a saber: aprendizagem entre pares, aprendizagem baseada em casos, aprendizagem mão na massa e aprendizagem baseada em projetos.

Tabela 1. Mapa de Aprendizagem Simplificado para a disciplina TICs na Educação no curso de Licenciatura em Pedagogia EaD.

\begin{tabular}{|c|c|c|}
\hline Semana & Tópicos & Estratégias de Avaliação \\
\hline 1 & 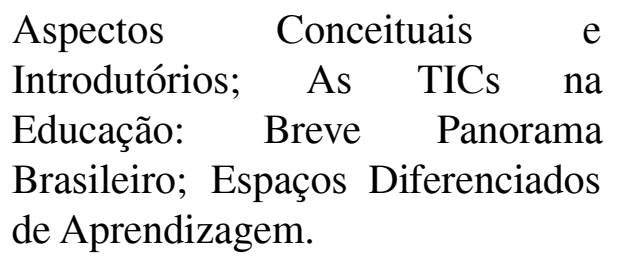 & $\begin{array}{c}\text { - Formulário de Autoavaliação e } \\
\text { Avaliação Diagnóstica por meio da } \\
\text { Ferramenta Google Forms } \\
\text { (individual). }\end{array}$ \\
\hline 2 & Visão Geral da área de Informática & - Fórum "Mão na Massa": Estudo de \\
\hline
\end{tabular}

http://basenacionalcomum.mec.gov.br/implementacao/praticas/caderno-de-praticas/aprofundamentos/193-tecnologias-digitais-da-informacao-e-comuni cacao-no-contexto-escolar-possibilidades 


\begin{tabular}{|c|c|c|}
\hline & $\begin{array}{l}\text { na Educação; Pesquisa-ação em } \\
\text { Informática na Educação; Mídias e } \\
\text { Softwares Educacionais. }\end{array}$ & $\begin{array}{l}\text { Caso (em duplas) - Tema: TIC na } \\
\text { Educação. }\end{array}$ \\
\hline 3 & $\begin{array}{l}\text { Tecnologias Web e Mobile } \\
\text { Educacionais; Ambientes Virtuais } \\
\text { de Aprendizagem e Redes Virtuais } \\
\text { de Aprendizagem; Aprendizagem } \\
\text { Ativa no Contexto Virtual e } \\
\text { Presencial. }\end{array}$ & $\begin{array}{l}\text { - Fórum "Mão na Massa": Uso do } \\
\text { Google Forms - Tema: } \\
\text { Possibilidades de Uso do Google } \\
\text { Forms na Educação (individual). }\end{array}$ \\
\hline 4 & $\begin{array}{l}\text { Objetos de Aprendizagem e } \\
\text { Recursos Educacionais Abertos; } \\
\text { Informática na Educação Especial } \\
\text { e Tecnologias Assistivas. }\end{array}$ & $\begin{array}{c}\text { - Fórum "Mão na Massa": Criação } \\
\text { de um Objeto de Aprendizagem (em } \\
\text { trios). }\end{array}$ \\
\hline 5 & $\begin{array}{l}\text { Tópicos em Informática na } \\
\text { Educação: } \\
\text { Inteligência Artificial na Educação; } \\
\text { Ambientes } \quad \text { Imersivos e } \\
\text { Aumentados; Empreendedorismo e } \\
\text { Startups Tecnológicas na área } \\
\text { Educacional; } \\
\text { Educacional. }\end{array}$ & $\begin{array}{c}\text { - Envio de Tarefa: Plano de Aula } \\
\text { para o Ensino Fundamental I } \\
\text { (Proposta de Intervenção com TICs e } \\
\text { Estratégias Ativas - em grupos de } 6 \text {, } \\
\text { reunindo subgrupos da tarefa } \\
\text { anterior). }\end{array}$ \\
\hline
\end{tabular}

No início da disciplina, os alunos foram informados sobre a atividade coletiva "Rumo ao Trabalho Prático Final da Disciplina", a ser desenvolvida ao longo das semanas 4 e 5, em grupos de 6 estudantes. Tal atividade, a ser apresentada durante a Avaliação Coletiva síncrona, tratou-se da produção de um Plano de Aula para uma determinada turma/ano do Ensino Fundamental I, inserindo-se uma proposta de Intervenção pedagógica com o uso de TICs e estratégias ativas de ensino e aprendizagem. A escolha do grupo, o referido plano poderia atender o ensino presencial, virtual ou híbrido, por meio do design de aprendizagem da proposta.

Era possível, mas não obrigatório, utilizar nesse projeto final os recursos criados nas semanas anteriores: Google Forms (semana 3) e um Recurso Educacional Aberto (semana 4). O template do plano de aula deveria conter: dados de identificação (Escola, Professores, Disciplina, Ano/Série); o tema específico a ser desenvolvido na proposta de aula; os objetivos a serem alcançados pelos alunos ao final da aula (ou da intervenção); a descrição metodológica para atingir os objetivos, fazendo uso de pelo menos uma ferramenta digital e uma estratégia ativa de ensino-aprendizagem; recursos didáticos (quadro, giz, datashow, plataforma para atividade síncrona, etc); estratégias de avaliação com base nos objetivos estabelecidos, que poderiam ser realizadas com diferentes propósitos (diagnóstica, formativa, somativa), bem como os critérios adotados para correção das atividades.

O mapa de aprendizagem da disciplina também incluiu um Encontro Síncrono para sanar dúvidas com a docente e outro para Avaliação Coletiva, além de uma 
Avaliação Individual pelo AVA do curso. Vale ressaltar que, durante o período de pandemia, essas avaliações foram realizadas de forma remota virtual, com auxílio do Google Meet. Num cenário normal, tais atividades avaliativas finais (coletiva e individual) ocorrem nos polos de apoio presencial, com mediação/facilitação dos professores mediadores/tutores, sob orientação dos professores responsáveis.

A Avaliação Coletiva consistiu na apresentação virtual dos Planos de Aula construídos ao longo das últimas semanas da disciplina de TICs na Educação. Nessa última etapa, torna-se fundamental para o processo de ensino e aprendizagem trocar experiências sobre a prática docente, razão pela qual foi realizado um debate sobre os planos produzidos. A reflexão sobre as possibilidades do que pode ser realizado ou o que pode ser aprimorado nas propostas é um avanço na construção de atividades que de fato impactam a aprendizagem dos estudantes. Num contexto real, a instituição poderia promover um momento de Mostra de Práticas Docentes, onde os professores e demais profissionais envolvidos teriam um espaço para compartilhar planos de aula, intervenções realizadas e os resultados alcançados. A atividade proposta na Avaliação Coletiva visou simular esse cenário e foi denominada "Mostra Virtual de Projetos de Práticas Docentes", uma vez que, em isolamento social ocasionado pela pandemia da COVID-19, não se esperava que os planos de aula fossem colocados em ação, apresentando-se os resultados. Nesse sentido, a palavra "projeto" foi compreendida como uma ação de planejamento e organização para futura aplicação. A atividade iniciou com o tutor relembrando como a ação ocorreria. A seguir, fez-se o sorteio da ordem de apresentação dos grupos. Cada grupo teve até 10 minutos para apresentar o Plano de Aula desenvolvido, sendo obrigatória a participação/fala de todos os integrantes. O tempo foi controlado pelo tutor, utilizando-se uma ferramenta de cronômetro online ou outra de seu conhecimento.

Na Avaliação Coletiva, deu-se destaque maior para a estratégia ativa principal, sorteada a cada grupo e descrita no Plano de Aula, observando-se alguns pontos principais: Qual é a estratégia? Como ela funciona de forma geral? Como a estratégia ativa será aplicada na execução do plano de aula? Quais os passos? Quais os recursos de apoio e interação? O que ocorrerá individualmente? O que será em grupo? Adicionalmente, também deveria ser dado destaque para a ferramenta digital descrita no Plano de Aula, também sorteada entre os grupos na Semana 5: Qual ferramenta? Para quê ela serve? Como pode ser usada? Como acessá-la? Precisa de configuração, qual ou quais? Ou seja, dedique um tempo da apresentação demonstrando aos demais colegas o funcionamento da ferramenta por meio de um exemplo criado para o Plano de Aula. Ao final das apresentações, o tutor conduziu um momento de reflexão e debate, considerando as seguintes questões: Os planos de aula apresentados são possíveis de serem colocados em prática? Poderiam ser facilmente replicados por outros docentes? A proposta de estratégia ativa e de ferramenta estão adequadas para a série e para o conteúdo selecionado? O plano de aula coloca o aluno como sujeito ativo no processo de ensino e aprendizagem? Qual o papel do professor na execução do plano de aula? Quais limitações podem ocorrer na aplicação do plano de aula? Muitas adaptações serão necessárias para aplicar o Plano de Aula no contexto inverso, ou seja, se planejado para contexto presencial, como seria a aplicação num contexto virtual? Há possibilidades/sugestões de aprimoramento das propostas?

A próxima seção descreve os resultados obtidos e auxilia a representação das etapas finais da EDR, a saber: reflexão e aprendizagem; e formalização da aprendizagem. 


\section{Resultados e Discussão}

Esta seção apresenta os resultados obtidos a partir da experiência educacional de ensino de TICs em ambiente educacional, para uma turma de 190 alunos de um curso de Licenciatura em Pedagogia EaD. A experiência ou intervenção foi pautada no uso de estratégias ativas e ferramentas digitais.

Na semana 2 da disciplina, depois de interagir com os materiais, foi proposto aos alunos buscar um artigo que relata um caso de uso de TICs no contexto escolar. Em duplas, deveriam extrair informações, tais como contexto, problema, intervenção feita com o uso da ferramenta, estratégia metodológica em sala de aula (física ou virtual), resultados obtidos, e registrá-las em um Google Docs compartilhado (Figura 3). Após isso, os alunos deveriam criar um podcast, por meio da ferramenta Anchor, apresentando oralmente o caso descrito no artigo lido. Essa atividade buscou preparar os alunos para: aprender a buscar casos e aprender com eles; organizar informações; compreender o desenvolvimento de intervenções com tecnologias; saber usar o Google Docs e a ferramenta de criação de podcasts, recursos que têm sido bastante utilizados.

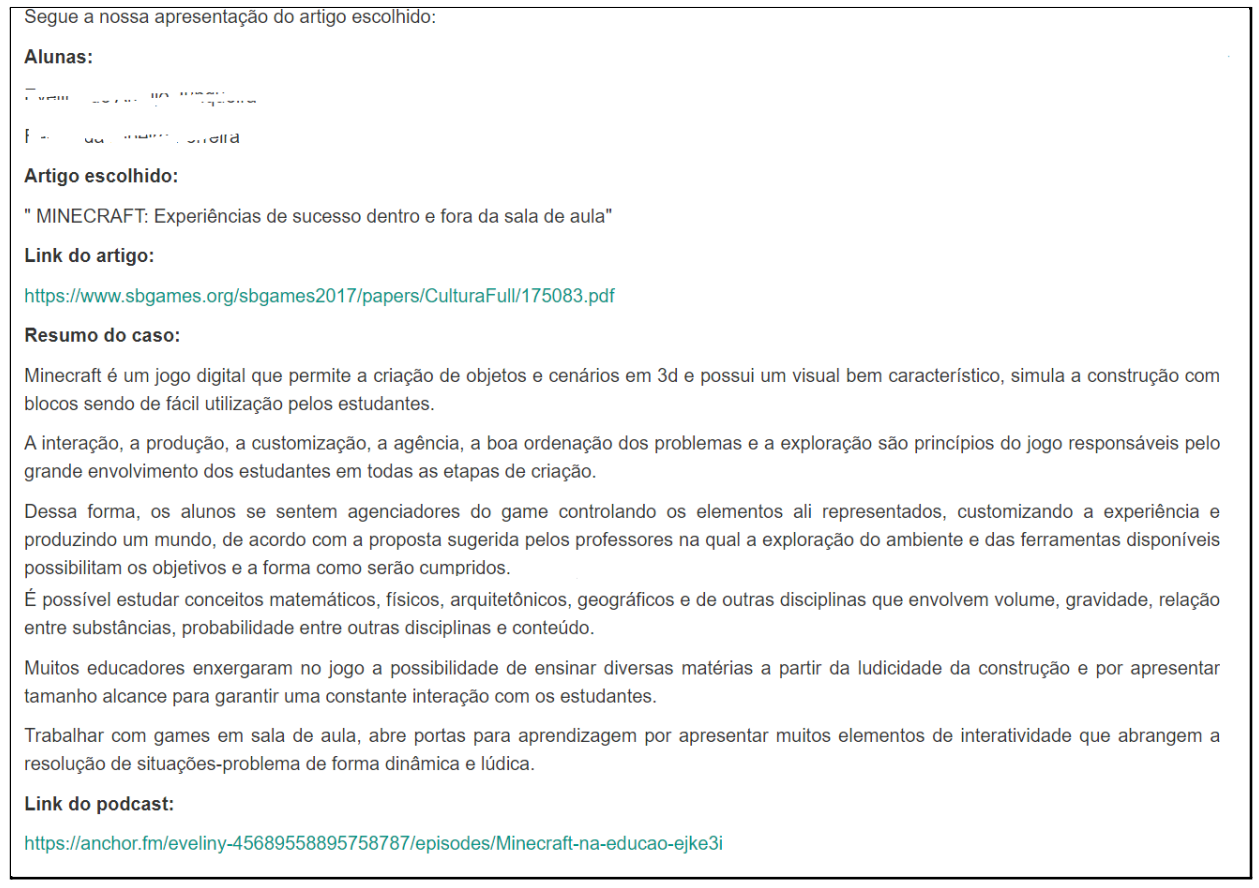

Figura 3. Exemplo de Resultado de Atividade Mão na Massa, Semana 2.

$\mathrm{A}$ atividade mão na massa, referente à semana 3, abordou Tecnologias Web e Mobile Educacionais e Computação em Nuvem. Os estudantes foram instigados a pensar usos do Google Forms no contexto educacional, seja ensino (educação infantil e ensino fundamental) ou no âmbito da gestão escolar. Ao final da atividade, esperava-se que eles fossem capazes de usar o Google Form (visão técnica, reflexão), criar um formulário pensando em possibilidades de aplicação num cenário educacional real (visão pedagógica, reflexão e ação) e perceber outras possibilidades por meio da interação com os demais colegas (socialização, reflexão, ampliação do campo de conhecimento, troca de experiências sobre o uso dessa ferramenta na educação). Além de usos tradicionais, como avaliações, pesquisas, os estudantes foram além, 
compreendendo a intencionalidade da ferramenta para os contextos escolhidos. A exemplo, cita-se o jogo de rimas (Figura 4). De acordo com os alunos autores, "o jogo pode ser usado como incentivador na construção da consciência fonológica da criança. O objetivo do jogo foi enaltecer a curiosidade, criatividade, atitude questionadora, a valorização e encantamento de cada criança da turma, além de proporcionar uma aprendizagem significativa". O jogo de rimas, criado no Google Forms, foi planejado para uma turma do $2^{\circ}$ ano do Ensino Fundamental I.

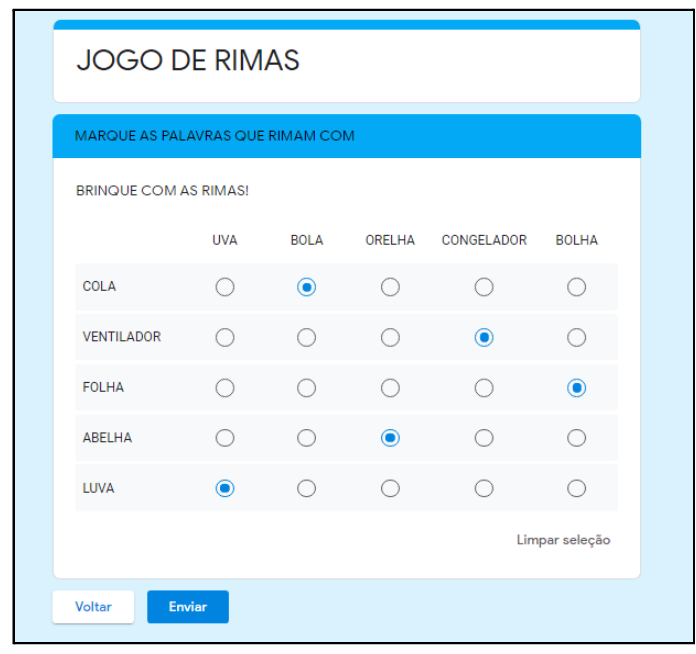

Figura 4. Exemplo de Resultado de Atividade Mão na Massa, Semana 3.

A primeira parte da Unidade 4 do Material Didático da disciplina abordou o conceito de Objetos de Aprendizagem ${ }^{3}$ (OAs). Um OA é qualquer recurso digital a exemplo de textos, animação, vídeos, imagens, aplicações, páginas Web em combinação que destinam-se a apoiar o aluno no processo de aprendizagem. Alguns OAs podem permitir maior interatividade por parte do aluno, outros menos. Normalmente, quanto mais recurso um OA possui, mais interativo ele é, mas isso exige um nível técnico de conhecimento mais profundo, por exemplo em programação de software. Para a semana 4, foi proposto que os alunos desenvolvessem um OA simples, com pouca ou nenhuma interatividade. Para auxiliar os grupos, foi criado um Fórum de Dúvidas Temático Ferramentas, inserindo-se nele referências e ideias de conteúdos sobre diversas ferramentas que pudessem ser utilizadas para criar o OA. Inicialmente, os alunos receberam orientações sobre o processo de construção de OAs. Eles deveriam criar OAs que pudessem ser reutilizados em diversos contextos; capazes de funcionar em diferentes dispositivos (computador e celular, por exemplo); e que pudessem ser postados no fórum para todos (colegas, tutores e professora). Adicionalmente, após postarem o OA do seu grupo, cada aluno deveria verificar os objetos dos demais colegas (pelo menos 3), e realizar uma postagem, dando feedback/avaliação sobre o trabalho dos colegas. Como resultados obtidos, foram criados jogos da memória com o PowerPoint ou com o Google Apresentações (Figura 5), recursos organizados na forma de Padlet ${ }^{4}$, quiz com o Excel, vídeos educacionais, jogos ou quizzes com o Google Forms, dentre outros.

\footnotetext{
${ }^{3}$ http://www.nuted.ufrgs.br/wordpress beta/?page id=2496

${ }^{4}$ https://pt-br.padlet.com/
} 


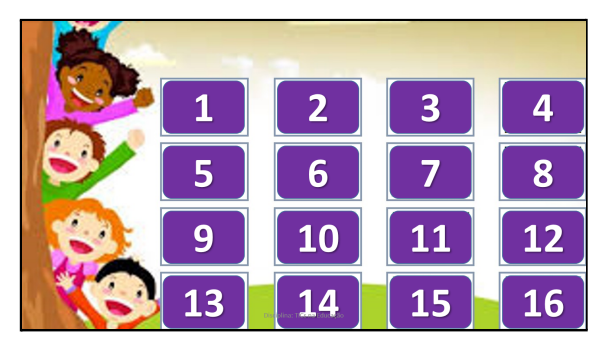

\section{Figura 5. Exemplo de Resultado de Atividade Mão na Massa, Semana 4, criação de um Objeto de Aprendizagem: Jogo da memória.}

Já na Avaliação Coletiva, os estudantes criaram projetos de Plano de Aula bastante inovadores, fazendo uso dos seguintes pares de estratégias ativas-ferramentas digitais, respectivamente: OPERA $^{5}$ e Mentimeter ${ }^{6}$; Seis chapéus do pensamento e Padlet; Aprendizagem Baseada em Jogos e Lightbot ${ }^{7}$; Aprendizagem Baseada em Projetos e Trello; Sala de Aula Invertida e AnswerGarden ${ }^{8}$; Think-Pair-Share e Google Apresentações; Rotação por estações de trabalho e Kahoot ${ }^{9}$.

Ao final de cada disciplina do curso citado, os alunos respondem um questionário de autoavaliação ${ }^{10}$. Desse, faz-se necessário destacar a questão específica que permitiu aos mesmos avaliar a estratégia docente utilizada, conforme a Figura 6, bem como alguns comentários que demonstram o nível de satisfação dos estudantes do curso de Pedagogia EaD na realização de atividades "mão na massa".

O fator de colocar a "mão na massa" nos proporcionou maior aprendizado; Essa disciplina foi uma das melhores de todo o curso de Pedagogia. Apresentou um conteúdo super atualizado e ferramentas TICs muito significativas para o processo de ensino $e$ aprendizagem; A disciplina foi tratada de forma prática e dinâmica, na minha opinião foi a abordagem mais satisfatória de todo o curso de licenciatura em Pedagogia.

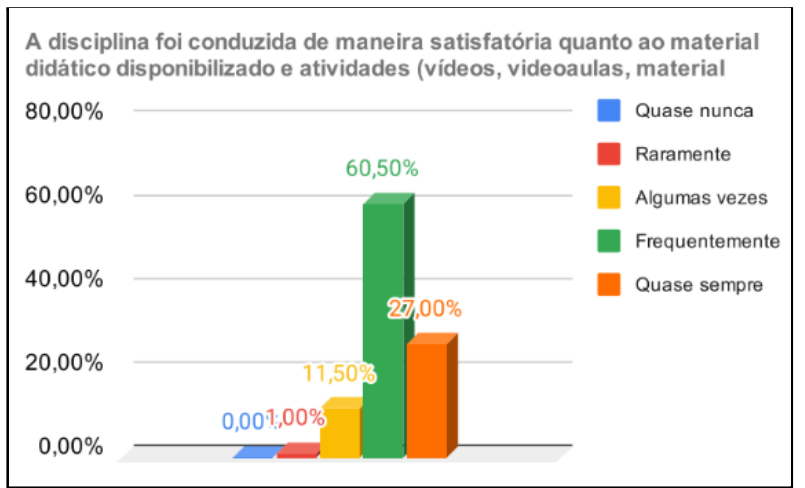

Figura 6. Resultado de uma das perguntas da Autoavaliação da Disciplina de TICs na Educação.

\footnotetext{
${ }^{5}$ https://www.world-changers.org/participatory-process-methods/210-opera

${ }^{6}$ https://www.mentimeter.com/pt-BR

${ }^{7}$ https://www.lightbot.com/

${ }^{8}$ https://answergarden.ch/

${ }^{9}$ https://kahoot.com/

${ }^{10} \mathrm{O}$ instrumento de avaliação utilizado está disponível em encurtador.com.br/iyzJW. Os comentários dos estudantes para a pergunta aberta podem ser conferidos em encurtador.com.br/hzFKO.
} 


\section{Conclusões}

De acordo com McKenney e Reeves (2018), os resultados obtidos a partir da implementação de uma intervenção no âmbito educacional podem ser compartilhados em todas as fases da Educational Design Research, mostrando que a interação com a prática está presente desde o início, mas aumentando o escopo, detalhamento e aprofundamento com o avançar do tempo. No âmbito da intervenção aqui relatada, o envolvimento com os estudantes e os tutores ocorreu ao longo de todo um semestre. Ajustes possíveis foram realizados no decorrer do mesmo. Melhorias estão sendo previstas para serem incorporadas nas próximas ofertas da disciplina, tais como aprimorar os templates que indicam para os alunos como as respostas devem ser postadas; ampliar o número de casos utilizados, tanto na apostila quanto nos vídeos de apoio; explorar outros tipos de estratégias ativas, tais como Educational Role-Playing Games ou RPG Educacional. Essa experiência com o ensino de TICs por meio de estratégias ativas e ferramentas digitais mostrou que, apesar de demandar maior tempo, esforço e dedicação dos estudantes, tutores e da professora, quando comparado ao uso de abordagens centradas no conteúdo e nos professores, para um contexto EaD, o engajamento nas atividades e a satisfação dos estudantes foi superior. Entretanto, precisamos avançar na coleta de evidências e análise estatística em relação a esse comparativo.

\section{Referências}

Barab, S. (2014). "Design-based research: A methodological toolkit for engineering change". In: The Cambridge Handbook of the Learning Sciences, Second Edition (pp. 151-170). Cambridge University Press.

BRASIL. Ministério da Educação. Base Nacional Comum Curricular. Brasília, 2018.

Fassbinder, A.G.O., Fassbinder, M., e Barbosa, E. F. (2016). "Um Conjunto Preliminar de Requisitos Pedagógicos para Caracterização e Comparação de Plataformas de MOOCs", In: Sánchez, J. Editor. Nuevas Ideas en Informática Educativa, Volumen 12, p. 167 - 176. Santiago de Chile.

McKenney, S., e Reeves, T. C. (2018). "Conducting educational design research". Routledge.

Plomp, T. e Nieveen, N. (2007). "An introduction to educational design research", In: Proceedings of the seminar conducted at the East China Normal University, Shanghai, (China).

Sein, M. K., Henfridsson, O., Purao, S., Rossi, M., e Lindgren, R. (2011). "Action design research". MIS quarterly, 37-56.

Silva, V., Silva, K., \& França, R. (2017). Pensamento computacional na formação de professores: experiências e desafios encontrados no ensino da computação em escolas públicas. In: Anais do XXIII Workshop de Informática na Escola, (pp. 805-814). Porto Alegre: SBC. doi:10.5753/cbie.wie.2017.805

Vieira, F., e Freire, E. (2018). Uma Análise dos Cursos de Licenciatura sobre a Formação Docente para Utilização das TICs na Educação. In: Anais do XXIV Workshop de Informática na Escola, (pp. 469-478). Porto Alegre: SBC. doi:10.5753/cbie.wie.2018.469 